\title{
O EMPirismo construtivo E O ARgumento de Musgrave: UM PROBLEMA OU UM PSEUDOPROBLEMA? ${ }^{1}$
}

\author{
Alessio Gava
}

Resumo: Em 1985, Alan Musgrave levantou uma séria objeção contra a possibilidade, por parte de um empirista construtivo, de traçar de maneira coerente a distinção - crucial para ele - entre observáveis e inobserváveis. Em sua sucinta resposta, no mesmo ano, Bas van Fraassen afirmou que o argumento de Musgrave funciona somente no interior da chamada "abordagem sintática" das teorias, porém, perde sua força no contexto da "visão semântica". Mas isso não é suficiente, segundo F. A. Muller, que publicou dois artigos (2004 e 2005), com o objetivo de estender a política epistêmica do empirismo construtivo. Para tanto, Muller propôs uma caracterização rigorosa da observabilidade, que só pode ser realizada utilizando-se a lógica modal. O resultado foi uma nova política epistêmica (mais ampla) para o empirismo construtivo, que o próprio Van Fraassen aparentemente endossou (MULLER; VAN FRAASSEN, 2008). Neste artigo, será mostrado que, todavia, a política epistêmica emendada de Muller é supérflua. Ademais, e sobretudo, o argumento de Musgrave parece, na verdade, ser um pseudoproblema.

Palavras-Chave: Empirismo construtivo. Observabilidade. Política epistêmica. Problema de Musgrave. Bas van Fraassen.

\section{INTRODUÇÁO: EMPIRISMO CONSTRUTIVO, OBSERVABILIDADE E LÓGICA MODAL}

O empirismo construtivo, vertente antirrealista proposta pelo filósofo holandês Bas van Fraassen, em seu seminal livro The scientific image (1980), é uma visão da ciência segundo a qual aceitar uma teoria científica significa acreditar que ela seja empiricamente adequada, ou seja, que todos os fenômenos observáveis atuais sejam representados diretamente por certas partes (as

1 O presente trabalho se beneficiou de conversas esclarecedoras com o Prof. Otávio Bueno, da University of Miami (EUA), ao qual registro meu agradecimento.

2 Professor de Matemática da Universidade Estadual do Paraná, Apucarana, PR - Brasil. E-mail: alessiogava@yahoo.it

Mestre e doutor em Lógica e Filosofia da Ciência pela Universidade Federal de Minas Gerais (UFMG), formado em Física pela "Università degli Studi di Trieste" (Itália).

http://dx.doi.org/10.1590/0101-3173.2018.v41n4.10.p177 
subestruturas empíricas) de algum modelo da mesma teoria. O próprio Van Fraassen ofereceu a seguinte explicação sumária do que isso significa: "Uma teoria é empiricamente adequada exatamente se é verdadeiro o que ela diz sobre as coisas observáveis e eventos no mundo - exatamente, se ela 'salva os fenômenos'” (VAN FRAASSEN [1980], 2007, p. 34).

Em 2005, em um artigo intitulado "The day of the dolphins", o mesmo autor reiterou o que aceitar uma teoria científica envolve, em termos de crença, segundo os ditames do empirismo construtivo: "O que as ciências falam acerca das partes observáveis do mundo é verdadeiro, o resto não interessa." (VAN FRAASSEN, 2005, p. 111, tradução nossa). Existiria, destarte, conforme F. A. Muller, uma epistemic policy dessa visão da ciência e de seus objetivos, segundo a qual um empirista construtivo acredita na verdade de todas as proposiçóes empíricas ${ }^{3}$ de teorias aceitas e permanece neutro com relação a todas as proposições não-empíricas das mesmas. Ainda segundo Muller (2004), a distinção entre observável e não-observável seria o pilar dessa "política epistêmica”.

Evidentemente, discriminar a parte observável do mundo daquela não-observável é, portanto, crucial para a proposta empirista de Van Fraassen. Com efeito, no prefácio à edição grega do The scientific image, de dezembro de 2004, ele escreve: "Para explicar minha visão do que é a ciência, e especificamente qual é seu objetivo, eu preciso de uma viável distinção entre o que é observável e o que não é." (VAN FRAASSEN, 2004, p. 1, tradução nossa). No livro, porém, não se deteve muito sobre tal questão, apesar de ser crucial. $\mathrm{Na}$ opinião do filósofo holandês, com efeito, não há como traçar a linha divisória de maneira não arbitrária, e observável é de fato um predicado vago, ${ }^{4}$ mas não é a análise filosófica que pode determinar o que é observável e o que é inobservável, e sim uma investigaçáo (científica) empírica.

No capítulo dois, igualmente, Van Fraassen propôs a seguinte indicação do que significa "ser observável": " $X$ é observável se há condições que são tais que, se $X$ nos estiver presente nessas condições, então vamos observá-lo." (VAN FRAASSEN, 2007, p. 40). A despeito da forma desse "guia grosseiro" (rough guide), todavia, ele defende não se tratar de uma questão modal. Afir-

\footnotetext{
${ }^{3}$ Na definição de Muller, empírica é uma proposição acerca de entidades reais e observáveis.

${ }^{4} \mathrm{O}$ fato de observável ser, como muitos levantaram, um predicado vago, parece não ser para Van Fraassen motivo de desconforto: "os predicados na linguagem natural são quase todos vagos, e nâo há nenhum problema em utilizá-los; mas apenas em formular a lógica que os dirige. Um predicado vago é útil desde que possua exemplos e contraexemplos claros." (VAN FRAASSEN, 2007, p. 40).
} 
mou isso de modo claro, em um artigo de 2003, que escreveu juntamente com Bradley Monton: "A propriedade de ser observável não é uma propriedade modal; por conseguinte, há fatos objetivos, não-modais, acerca do que é observável.” (MONTON; VAN FRAASSEN, 2003, p. 405, tradução nossa).

Ainda que o essencial termo observável tenha sido analisado em termos de contrafactuais, a observabilidade, para Van Fraassen, não é uma propriedade modal, porém, um fato do mundo. Ela depende do contexto, isto é, diz respeito à relação entre a comunidade epistêmica e o mundo. Trata-se de uma propriedade factual: as limitações do organismo humano e a constituição do mundo são fatos, que podem ser determinados através de uma investigação empírica - e não linguística.

A propriedade "ser observável" tem, desse modo, o mesmo estatuto da propriedade "ser feito de madeira" ou "ser picante". Que a mesa da cozinha do Sebastião seja feita de madeira é um fato objetivo, o qual, em caso de dúvida, pode ser verificado empiricamente. Que a pimenta malagueta seja picante é também um fato objetivo, que concerne à relação entre o mundo (do qual a pimenta faz parte) e nós, seres humanos (para os quais a pimenta provoca sensação de ardência). A ciência, eventualmente, pode nos fornecer uma descrição/explicação desse fato, em termos da composição química da malagueta e da constituição do organismo humano, contudo, nesse caso, diria Van Fraassen, o que ela faz é simplesmente revelar algo acerca do mundo e não estabelecer isso. $\mathrm{O}$ mesmo acontece no caso da observabilidade.

Com o artigo de 2003, Van Fraassen parece assim ter conseguido evitar o recurso à lógica modal. ${ }^{5}$ Apenas um ano depois, todavia, Muller achou conveniente propor um critério rigoroso para estabelecer se um dado objeto é ou não é observável e, para tanto, lançou mão justamente da lógica modal. A motivar Muller foi uma objeção que Alan Musgrave tinha levantado, ainda em 1985, contra a possibilidade de se traçar de maneira coerente a distinção observável/não-observável, no interior do empirismo construtivo (MUSGRAVE, 1985). Para contornar o "problema de Musgrave", Muller propôs uma nova política epistêmica para o empirismo construtivo, baseada justamente em seu critério de observabilidade.

\footnotetext{
${ }^{5}$ No texto, Van Fraassen ainda defende que, de qualquer modo, realismo modal e empirismo construtivo são perfeitamente compatíveis, respondendo assim a uma objeçâo que James Ladyman fizera, em seu artigo "What's really wrong with constructive empiricism?: Van Fraassen and the metaphysics of modality", de 2000. O artigo dele e de Monton de 2003 surgiu, justamente, em decorrência da objeção de Ladyman e constitui uma resposta a essa.
} 
O objetivo deste estudo é analisar o argumento de Musgrave, a resposta inicial de Van Fraassen, as objeçôes de Muller e a "política epistêmica emendada" que este propôs, para mostrar que, afinal, tratava-se provavelmente apenas de um pseudoproblema.

\section{O “problema de Musgrave”}

Em 1985, no artigo "Empiricism in the philosophy of science", Van Fraassen se deteve sobre uma objeção que Musgrave levantara contra a possibilidade de um empirista construtivo traçar de maneira coerente a distinção observávellinobservável (MUSGRAVE, 1985), por achar que isso permitiria esclarecer o conceito de adequação empírica e suas implicaçóes.

Em sua contribuição ao volume intitulado Imagens of science: essays on realism and empiricism, with a reply from Bas C. van Fraassen, Musgrave afirmou haver uma incoerência de fundo insuperável em traçar uma distinção entre observáveis e inobserváveis, quando se permanece fiel aos princípios do empirismo construtivo. $\mathrm{O}$ argumento dele é que, se é próprio da ciência desvelar o que é observável e o que não é, a teoria onde isso acontece deve, evidentemente, ser aceita pelo seu usuário. Ora, se o usuário for um empirista construtivo, a aceitação da teoria implica a crença da verdade de suas sentenças acerca de entidades observáveis, tais como, justamente, " $A$ é observável”. Com relação aos inobserváveis, por outro lado, o juízo será suspenso e isso se aplica, segundo Musgrave, também a sentenças acerca desses, tais como " $B$ é inobservável”. Um empirista construtivo coerente não poderia assim acreditar na afirmação ou na postulação, feita por uma teoria que ele aceita e considera empiricamente adequada, de que um dado fenômeno náo-observável seja, de fato, inobservável para os seres humanos. Ou seja, conclui Musgrave, "o empirismo construtivo requer uma dicotomia que náo pode traçar de maneira consistente." (MUSGRAVE, 1985, p. 209, tradução nossa). ${ }^{6}$

Images of science é concluído com o artigo de Van Fraassen mencionado, "Empiricism in the philosophy of science", no qual se encontra uma breve resposta a Musgrave. Com relação à suposta impossibilidade de traçar a distinção observávellinobservável de maneira coerente, por parte de um empirista

\footnotetext{
6 Vale acrescentar que, se o empirista construtivo aceita certa teoria, entâo ele aceita também as afirmaçóes dessa acerca de entidades (postuladas) inobserváveis. O ponto salientado por Musgrave é que, porém, na opiniāo dele, os princípios do empirismo construtivo não permitiriam dar um passo ulterior, o qual levaria até à crença na verdade dessas sentenças.
} 
construtivo, o filósofo holandês conjectura que essa objeção tenha surgido por ele não ter sido suficientemente claro, na exposição do conceito de adequação empírica. Van Fraassen então retoma o exemplo proposto por Musgrave, considera uma teoria $T$ e a sentença " $B$ não é observável para os seres humanos" e escreve:

Suponhamos que $T$ inclua tal sentença. Então, $T$ não possui nenhum modelo em que $B$ ocorre nas subestruturas empíricas. Portanto, se $B$ é real e observável, nem todos os fenômenos observáveis cabem em um modelo de $T$ da maneira correta, de modo que $T$ não é empiricamente adequada. Consequentemente, se eu acredito que $T$ é empiricamente adequada, logo eu também acredito que $B$ é inobservável, se for real. Acho que isso basta. (VAN FRAASSEN, 1985a, 256, tradução nossa).7

Jeffrey Sicha, autor de uma resenha a Images of science, considera-se convencido do fato de que Van Fraassen conseguiu, no artigo final, responder à maioria, talvez todas, das objeçóes levantadas no livro (SICHA, 1992, p. 519) - que foi publicado cinco anos após $A$ imagem cientifica e contém dez trabalhos selecionados entre os numerosos estudos que tinham a obra de Van Fraassen como objeto. Quanto ao "problema de Musgrave", todavia, nem todos concordam com Sicha. Conforme relata Muller, o primeiro a declarar-se insatisfeito com a resposta de Van Fraassen foi o próprio Musgrave: "Van Fraassen (1985a, p. 256) forneceu uma resposta sucinta para a crítica de Musgrave, que Musgrave (2002) confessou não entender, [acrescentando:] 'e ninguém para quem eu tenha perguntado conseguiu me explicar." (MULLER, 2004, p. 638, tradução nossa).

Vamos tentar apresentar o argumento de Van Fraassen de um modo que facilite sua compreensão, já que Musgrave não é o único a ter achado a resposta do filósofo holandês pouco clara. Para tanto, utilizaremos um mínimo de linguagem lógica, tendo como referência inclusive o trabalho realizado por Muller, em 2004 e 2005, para se chegar a uma definição rigorosa de "observável", que justamente foi inspirada pela objeçáo de Musgrave.

Dada uma teoria $T$, portanto, adotaremos as seguintes convençôes:

- $\operatorname{Emp} A d(T)$ significa que a teoria $T$ é empiricamente adequada;

- $\quad T^{*}$ é uma subestrutura empírica de $T\left(\operatorname{logo}, T^{*} \subset T\right)$;

$7 \mathrm{O}$ argumento é reproposto, praticamente com as mesmas palavras, no prefácio à edição italiana do Scientific Image, publicada no mesmo ano. 
- $\quad B$ é uma entidade inobservável postulada por $T$;

- $\Phi(B)$ é a sentença " $B$ não é observável para os seres humanos";

- $\quad o b s(B)$ significa " $B$ é observável” e real $(B)$ significa " $B$ é real”;

- “ $T$ inclui a sentença $\Phi(B)$ ” será expresso como $T \rightarrow \Phi(B)$ e não como $\Phi(B) \in T$, já que, na visão de Van Fraassen, uma teoria é um conjunto de modelos e náo de sentenças.

Empregando a simbologia apresentada, a resposta de Van Fraassen ao argumento de Musgrave pode ser expressa da seguinte maneira:

$$
\left[(T \rightarrow \Phi(B)) \rightarrow\left(B \in T \wedge B \notin T^{*}\right)\right] \rightarrow[(\operatorname{real}(B) \wedge \operatorname{obs}(B)) \rightarrow \sim \operatorname{Emp} A d(T)] .
$$

Disso se segue, como corolário (a palavra que Van Fraassen usa, no prefácio à edição italiana do Scientific Image):

$\left[\left(\operatorname{Emp} A d(T) \wedge B \in T \wedge B \notin T^{*}\right) \rightarrow \sim(\operatorname{real}(B) \wedge \operatorname{obs}(B))\right] \rightarrow(\operatorname{real}(B) \rightarrow \sim o b s(B))$.

O fato de $B$ ser inobservável, se for real, uma vez que se trata de uma entidade postulada por uma teoria, deriva logicamente da adequação empírica dessa última, pois isso significa que todos os fenômenos observáveis são corretamente descritos por uma subestrutura empírica de, pelo menos, um modelo da própria teoria. Vale aqui salientar que o diagnóstico de Van Fraassen em relação ao surgimento da objeção de Musgrave foi justamente o fato de o conceito de adequação empírica ter sido compreendido de modo apenas parcial e não satisfatório, como ressaltamos anteriormente.

Para melhor entender por que $B$ é inobservável se for real, notamos que, se $B$ não pode ser ao mesmo tempo real e observável, pois se trata de uma entidade postulada pela teoria (empiricamente adequada) mas que não é contemplada nas subestruturas empíricas dos modelos dessa, então existem (em princípio) três possibilidades:

(a) $B$ é real e inobservável;

(b) $\quad B$ é não-real e observável;

(c) B é não-real e inobservável. 
Fica assim claro que, se $B$ for real, somente poderia ser inobservável, conforme assevera (corretamente) Van Fraassen. E se $B$ fosse não-real? Nesse caso, apesar de ter sido apresentada, a alternativa (b) não constitui uma possibilidade efetiva, já que uma teoria que postulasse uma entidade fictícia (observável) não seria empiricamente adequada. Com efeito, se $B$ fosse não-real mas observável, então ela ocorreria nas subestruturas empíricas dos modelos da teoria (os quais, por serem modelos da teoria, incluem todas as entidades postuladas) e assim não seria possível haver um isomorfismo entre a subestrutura empírica de pelo menos um desses modelos e o mundo. ${ }^{8}$ Uma vez que uma teoria fosse empiricamente adequada, portanto, as únicas possibilidade efetivas seriam (a) e (c).

Ora, disso decorre, evidentemente, que $B$ seria inobservável tanto no caso em que ela existisse quanto no caso em que se tratasse de uma entidade fictícia. Portanto, a hipótese da adequação empírica de uma teoria implica, na verdade, a conclusão mais forte de que uma entidade por essa postulada como inobservável é de fato inobservável (independentemente do estatuto ontológico da mesma). Van Fraassen, entretanto, limitou-se a afirmar que tal entidade é inobservável se for real. Por que "se contentou" com essa consequência mais fraca da hipótese da adequação empírica da teoria? Talvez ele considere que não faria muito sentido admitir a possibilidade de uma entidade inobservável ser inclusive não-real: qual seria a utilidade dela, na economia da teoria?

De fato, o agnosticismo propugnado pelo empirismo construtivo com relação à existência das entidades inobserváveis postuladas por uma teoria corresponde a não querer comprometer-se ontologicamente, ao passo que, porém, é admitida a possibilidade de as mesmas entidades existirem. Tanto que um empirista construtivo concebe que os cientistas assumem a existência de elétrons e ribossomos como "hipótese de trabalho", ao realizar aquilo que Van Fraassen chama de "imersão teórica" no mundo desenhado pela teoria. Se os cientistas partissem do pressuposto de que elétrons e ribossomos não existem, com efeito, trabalhar com teorias que os contemplam não faria muito sentido, evidentemente.

\footnotetext{
${ }^{8}$ Além da noção "grosseira" de adequação empírica (cf., por exemplo, MONTON; VAN FRAASSEN 2003, p. 406) - que parece corresponder, contudo, àquilo que Van Fraassen de fato tem em mente, quando faz referência a esse conceito -, há aquela formal, na qual se alude a um isomorfismo entre a parte observacional de um modelo de uma teoria e um modelo de dados construído a partir das aparências (VAN FRAASSEN, 2008, p. 168, 238; GIERE, 2009, p. 107-108).
} 
Essas nossas consideraçóes, que achamos difícil pensar que não tenham sido tecidas também por Van Fraassen, levariam de fato a manter como única conclusão realmente plausível aquela segundo a qual a entidade $B$ é real e inobservável. Contudo, por tratar-se de algo que nunca poderá ser atestado empiricamente, mais prudente é admitir inclusive a conclusão (c), por ela ser legítima do ponto de vista lógico, apesar de não parecer muito razoável.

Importante, todavia, é salientar que a inobservabilidade da entidade $B$ está efetivamente atestada por meio de um raciocínio estritamente lógico, como consequência dedutível das premissas comuns dos argumentos de Musgrave e de Van Fraassen, de que uma teoria aceita (e, portanto, empiricamente adequada, segundo Van Fraassen) afirma que aquela entidade é inobservável. Ora, o filósofo holandês declarou: "se eu acredito que $T$ é empiricamente adequada, então eu também acredito que $B$ é inobservável se for real” (VAN FRAASSEN, 1985a, p. 256, tradução e grifo nosso), como vimos. Disso se depreende que a crença na adequação empírica de uma teoria implica (também) a crença nas consequências lógicas dessa assunção, o que parece ser relativamente óbvio: um empirista construtivo não acredita somente na verdade das proposiçóes que dizem respeito à existência das entidades observáveis postuladas por uma teoria empíricamente adequada (porque, nesse caso, a verdade dessas foi atestada empiricamente, através da observação), mas também nas "verdades lógicas", até aquelas matemáticas, e, por conseguinte, acredita inclusive nas consequências logicamente dedutíveis da teoria em questão.

Assim, por exemplo, um empirista construtivo está certamente legitimado em acreditar na verdade da sentença ("não-empírica", segundo a definição de Muller) "dezessete é um número primo", mesmo que o número dezessete não seja observável (VAN FRAASSEN, 2007, p. 38). Esse parece ser um ponto importante que escapou tanto a Musgrave quanto a Muller, conforme veremos, a ponto de gerar, de fato, um "pseudoproblema” e não uma efetiva ameaça para o empirismo construtivo. Entretanto, apesar de a crença nas verdades da lógica ser obviamente legítima até para um empirista construtivo, e de essa consideração parecer implícita na resposta de Van Fraassen a Musgrave, recentemente, o próprio filósofo holandês achou oportuno emendar a política epistêmica que Muller considerou ser própria do empirismo construtivo, justamente para responder (novamente) à objeção de Musgrave que apareceu em Images of science.

Por essa razão, mas também porque ajudam a esclarecer importantes aspectos relacionados ao crucial - particularmente na perspectiva do empiris- 
mo construtivo - conceito de observabilidade, serão aqui analisados os trabalhos de Muller, o qual, entre 2004 e 2005, propôs um critério rigoroso para estabelecer se um dado objeto é ou não observável, com o intuito de tentar solucionar o "problema de Musgrave", uma vez que achou insuficiente a resposta inicial de Van Fraassen.

\section{A definição rigorosa de Muller}

Pouco mais de dez anos atrás, o holandês F. A. Muller publicou dois artigos, "Can a constructive empiricist adopt the concept of observability?" (2004) e "The deep black sea: observability and modality afloat" (2005), nos quais analisou a objeção de Musgrave discutida na seção anterior e concluiu que a única saída, para responder de maneira efetivamente satisfatória, é estender a política epistêmica do empirismo construtivo. Mas isso, ele asseverou, "requer um profundo mergulho no significado do conceito de observabilidade, na sua relação com a modalidade no interior do empirismo construtivo e nas condiçóes de verdade de $O b s(X)$ [a sentença ' $X$ é observável']." (MULLER 2004, p. 653, tradução nossa).

Conforme salientou Muller (2004, p. 651-652), entretanto, o argumento de Musgrave está fundamentado na tácita assunção de que nossos julgamentos acerca da observabilidade de um objeto (existente ou não) devem basear-se em alguma teoria científica aceita. Isso contradiz certamente o requisito fundamental para o empirismo construtivo e, provavelmente, para qualquer posição empirista: observabilidade e observação são (e devem ser julgados como) fatos do mundo, independentes de qualquer teoria. Com efeito, Van Fraassen poderia ter "desmontado" o argumento de Musgrave de forma muito mais rápida, compreensível e eficaz, se tivesse simplesmente respondido que, se quiséssemos traçar, no mundo, a distinção entre observáveis e inobserváveis a partir daquilo que a teoria propóe, a consequência seria uma "catástrofe lógica", como se lê em $A$ imagem cientifica: "[A observabilidade é] uma função de fatos sobre nós qua organismos no mundo [...] mas não há o tipo de dependência de teorias ou relatividade que pudesse causar aqui uma catástrofe lógica." (VAN FRAASSEN, 2007, p. 117). ${ }^{9}$

Admitindo não ser, ao invés, suficiente a breve resposta dada inicialmente por Van Fraassen, Muller retomou a objeçâo de Musgrave. "Elétrons

\footnotetext{
${ }^{9}$ É efetivamente estranho que Van Fraassen não tenha feito isso. Muller, porém, defende a legitimidade do pressuposto de Musgrave (se não, o sucessivo argumento dele também seria perdido).
} 
são inobserváveis" é, evidentemente, uma proposição que não diz respeito a algo ao mesmo tempo observável e real (é "não-empírica", segundo a definição de Muller), porque acerca de uma partícula inobservável e, frente a ela, um empirista construtivo deveria manter uma postura de neutralidade, conforme recomenda a política epistêmica de sua vertente antirrealista. Por conseguinte, esse não poderia acreditar nela, mas deveria limitar-se a uma mera aceitação da mesma (MULLER, 2004, p. 645).

Em seguida, Muller elabora e formaliza, mediante a linguagem lógica, a crítica de Musgrave, acreditando que ela de fato leve a um problema, o qual batizou de "o problema de Musgrave", e alegando que esse somente poderia ser resolvido modificando a política epistêmica do empirismo construtivo (MULLER, 2004, p. 646-647, 2005, p. 88-89). Além disso, seria necessário estabelecer, também, de forma rigorosa, o que significa o termo "observável”.

O "problema de Musgrave" seria aquele de explicar como poder adquirir, no interior do empirismo construtivo, a crença de que certa entidade $X$ é observável ou a crença de que $X$ é inobservável. Ele deve ser solucionado, afirma Muller. Não pode ser suficiente limitar-se à mera aceitação de sentenças, como "elétrons são inobserváveis", pois, para poder distinguir entre a parte das teorias na qual acreditar e a parte que, pragmaticamente, somente é aceita, é fundamental traçar uma linha objetiva, e isso exige a crença na verdade até de sentenças que afirmam a eventual inobservabilidade de entidades postuladas por essas teorias (MULLER, 2004, p. 646); cf. também (DICKEN; LIPTON, 2006, p. 232-233). ${ }^{10}$

Para que isso possa ser realizado, assinala Muller, o "guia grosseiro" de "observável" deve ser interpretado na perspectiva da abordagem semântica que Van Fraassen introduziu no estudo das teorias científicas. Nessa caracterização, sustentar que " $X$ é observável se há condições que são tais que, se $X$ nos estiver presente nessas condiçôes, entáo vamos observá-lo" (VAN FRAASSEN 2007, 40) equivaleria a dizer, grosso modo, que $X$ é observável se existe pelo menos um modelo da teoria em questão em que $X$ é observado de fato. ${ }^{11}$

\footnotetext{
${ }^{10}$ Vale aqui relevar que Muller parece considerar que, contrariamente a uma opiniăo muito difusa sobre o empirismo construtivo, a fronteira entre crença e neutralidade não deveria espelhar a linha que separa os observáveis dos inobserváveis, já que ele quer que os empiristas construtivos acreditem em sentenças acerca do estatuto observacional de qualquer entidade.

${ }^{11} \mathrm{Na}$ verdade, Muller (2005, p. 82) se utiliza da seguinte formulação do "guia grosseiro": "o objeto concreto $X$ é observável se existem circunstâncias que são tais que $X$ nos está presente e nós observamos $X^{\prime \prime}$ (traduçấo nossa), mas ela é certamente equivalente àquela presente em $A$ imagem científica.
} 
Mais precisamente, o critério rigoroso de observabilidade proposto por Muller, traduzido em linguagem corrente, afirma que o objeto $X$ é observável (para a comunidade epistêmica $\varepsilon$ e considerando o subconjunto $L$ de modelos da teoria ondulatória da luz, que contêm a comunidade epistêmica $\varepsilon$, uma fonte de luz e o objeto $X$ ) sse, para todo $p$, membro da comunidade epistêmica $\varepsilon$, existe pelo menos um modelo $M$, entre aqueles do subconjunto $L$ de modelos da teoria, no interior do qual é verdade que $p$ está na presença do objeto concreto $X$ e $p$ vê (observa) $X$ (MULLER, 2005, p. 82-83).

$\mathrm{Na}$ linguagem lógica utilizada por Muller (que traduzimos para o português), a mesma definição/critério de "observável" é expressa da seguinte maneira: $\operatorname{Obs}(X, \varepsilon, L)$ sse $\forall p \in \varepsilon, \exists M \in L: \operatorname{verd}(M, \operatorname{Frente}(p, X) \wedge \operatorname{Ve}(p, X))$. (MULLER, 2005, p. 83, tradução nossa).

Muller demonstra, em seguida, que, usando essa definição/critério, resolvem-se tanto o "problema de Musgrave" quanto outros que ele chama de o "problema do contexto" e o "problema de Psillos".

Para se chegar à solução do primeiro problema, que foi o que o impulsionou a "mergulhar" no conceito de observabilidade, Muller propóe modificar aquela que tinha chamado de "política epistêmica do empirismo construtivo". Para tanto, lança mão de sua definição de "observável", que fornece condiçóes de verdade verificáveis para $\operatorname{Obs}(X, \varepsilon, L)$. "Nada nos impede de prescrever que um empirista construtivo deveria acreditar que (é verdade que) $X$ é observável se $\operatorname{Obs}(X, \varepsilon, L)$ é verdadeiro; e acreditar que (é verdade que) $X$ é inobservável se $\operatorname{Obs}(X, \varepsilon, L)$ é falso. O problema de Musgrave é assim resolvido." (MULLER, 2005, p. 89, tradução nossa); cf., também, Muller (2004, p. 653).

Aquilo que Muller chama de o "problema do contexto", diferentemente, surgiu em decorrência do artigo de 2003 que Van Fraassen escreveu em conjunto com Bradley Monton, o já mencionado "Constructive empiricism and modal nominalism". Nele, Van Fraassen esclareceu que o "guia grosseiro" presente em $A$ imagem cientifica deve ser entendido como contrafactual (condicional subjuntivo com um antecedente falso), senão todas as entidades que não nos estão presentes seriam observáveis (MONTON; VAN FRAASSEN, 2003, p. 410), pois, quando o antecedente é falso, o condicional é verdadeiro, como se sabe da lógica. Ora, se, em $A$ imagem científica, Van Fraassen tinha negado que os contrafactuais tenham valor de verdade objetivo (VAN FRAASSEN, 2007, p. 36), no artigo de 2003 elucidou que "o sentido em que 
os contrafactuais são julgados não possuir um valor de verdade objetivo é que, em geral, eles dependem do contexto. [...] O condicional tem um valor de verdade, relativamente a tal contexto; mas tal valor irá variar de acordo com o contexto." (MONTON; VAN FRAASSEN, 2003, p. 411, tradução nossa).

Mas o que seria o contexto? O termo parece até mais vago do que $o b$ servável. Monton e Van Fraassen, de fato, não são nem um pouco claros a esse respeito. Muller discorda do recurso a ele: parece mais um deus ex machina do que uma solução (MULLER, 2005, p. 69, nota 12). Eis que, segundo Muller, o critério rigoroso de observabilidade por ele proposto oferece uma solução também para o "problema do contexto", na medida em que é o conjunto dos modelos permitidos pela teoria eletromagnética da luz que constitui o conjunto de contextos onde o "guia grosseiro" (quando interpretado ou formulado como contrafactual) possui um valor de verdade objetivo.

O "problema de Psillos", ao invés, é aquele de saber quais "contextos de ficção científica” são permitidos, quando se pensa em observabilidade. Citando o fato de que Van Fraassen considera as luas de Júpiter observáveis, porque os astronautas poderiam vê-las (sem ajuda de instrumentos) também de perto (VAN FRAASSEN, 2007, p. 41), Stathis Psillos se perguntou, em um artigo de 1999, se então qualquer contexto ficcional é permitido e se, como consequência, não poderíamos considerar células e micróbios (supostamente) presentes no sangue humano como observáveis (porque poderíamos reduzir de tamanho um cientista e injetá-lo na veia de um indivíduo ou, em alternativa, aumentar o tamanho dessas células até elas se tornarem visíveis) (MULLER, 2005, p. 67-68).

Nesse caso, também, Muller entende que o critério de observabilidade por ele proposto oferece uma resposta ao problema: nem todos os contextos ficcionais são permitidos, mas somente aqueles que correspondem a pelo menos um modelo de $L$. Modelos nos quais a fisiologia dos seres humanos é modificada, como seriam aqueles em que um cientista é reduzido ao tamanho de uma célula, não são permitidos. Viagens interplanetárias, nas quais os astronautas não sofrem modificaçôes do ponto de vista fisiológico (como em uma viagem até Júpiter) são permitidas. Problema resolvido (MULLER, 2005, p. 88).

Com isso, o círculo aparentemente se fecha e essa caracterização do que significa observável afigura-se viável para os objetivos de Van Fraassen. A definição de Muller, com efeito, deveria possibilitar traçar a linha divisória en- 
tre observáveis e inobserváveis de maneira precisa e objetiva e ela foi proposta exatamente em uma época em que o próprio Van Fraassen aparentou ter-se convencido da necessidade de fixar claramente o significado de "observável", não podendo basear a sua própria vertente filosófica em um conceito vago.

Ademais, além de consentir estabelecer de forma clara se certa entidade é observável ou não, a definição de Muller faz com que o conteúdo empírico da teoria seja definido de dentro da ciência, por meio de uma distinção feita pela própria ciência entre o que é observável e o que não é, segundo um dos principais desiderata do empirismo construtivo (VAN FRAASSEN, 2007, p. 149).

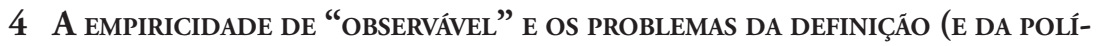 TICA EPISTÊMICA) DE MULLER}

Já dizia o velho ditado que "quando a esmola é demais, o santo desconfia”, e isso, ao que parece, aplica-se infelizmente até à definição de Muller que acabamos de discutir. Essa, além de resolver o "problema de Musgrave", solucionaria mais duas outras questôes de uma vez só, mas tem o "vício de origem", fatal, de ser teoricamente dependente.

Ora, é verdade que, em $A$ imagem cientifica, encontra-se escrito que "para encontrar os limites do que é observável no mundo descrito pela teoria $T$, devemos perguntar à própria teoria $T$ e às teorias utilizadas como auxiliares no teste e na aplicação de $T$ " (VAN FRAASSEN, 2007, p. 110), mas Van Fraassen deixa bem claro que isso não deve levar a pensar que a extensão do adjetivo observável seja "decidida" pela ciência. Com efeito, na página seguinte, escreve:

Aceitar uma teoria não envolve mais crença de que o que a teoria diz sobre os fenômenos observáveis é correto. Contudo, para delinear o que é observável, devemos examinar a ciência - e possivelmente aquela mesma teoria -, pois isso também é uma questão empírica. Isso poderia gerar um círculo vicioso se aquilo mesmo que é observável fosse não simplesmente um fato revelado pela teoria, mas, ao contrário, algo relativo a teorias ou dependente delas. Já vai estar perfeitamente claro que nego isso; encaro o que é observável como uma questão independente de teorias. Trata-se de uma função de fatos sobre nós qua organismos no mundo [...] - mas não 
há o tipo de dependência de teorias ou relatividade que pudesse causar aqui uma catástrofe lógica. (VAN FRAASSEN, 2007, p. 111, grifo nosso). ${ }^{12}$

Se quisermos saber o que certa teoria classifica como observável, olhar para a própria teoria é obviamente o mais apropriado a se fazer. Se quisermos saber o que é observável no mundo, podemos até usar aquela teoria como uma sorte de guia, mas isso não torna a observabilidade teoricamente dependente. Analogamente, podemos até consultar a lista telefônica para saber qual é o endereço da Secretaria de Pós-graduação, mas isso não significa que a localização espacial da secretaria dependa daquilo que está escrito na lista telefônica, pois essa simplesmente revela o endereço e não o determina (e pode muito bem conter informaçóes erradas, inclusive). Ou seja, a localização espacial da secretaria é um fato do mundo.

Muller está obviamente ciente da posição de Van Fraassen acerca dessa questão, tanto que ele mesmo faz referência à passagem de $A$ imagem científica citada acima e transcreve uma outra do artigo que Van Fraassen redigiu em coautoria com Monton, onde o mesmo ponto é reafirmado. Muller admite que, como é evidente, a própria definição de observabilidade "depende da teoria científica $L$ ” (MULLER, 2005, p. 85, tradução nossa), mas defende a proposta que fez, lembrando como o próprio Van Fraassen afirma, no mesmo artigo de 2003, que a questáo da observabilidade é independente das teorias "em princípio", contudo, na prática, devemos recorrer às melhores teorias aceitas para saber se certa entidade é observável ou não (MULLER, 2005, p. $84,86)$. Isso aconteceria porque "nem toda a pesquisa empírica foi realizada, portanto, temos que nos apoiar nas nossas melhores teorias em uso." (MONTON; VAN FRAASSEN, 2003, p. 415, tradução nossa).

Assim, parece que, em "Constructive empiricism and modal nominalism", é sustentado algo um pouco diferente, a saber, que existem casos nos quais a resposta acerca do estatuto observacional de uma entidade somente pode ser encontrada consultando-se uma teoria (que contempla tal entidade), já que uma pesquisa empírica sobre a mesma ainda não foi realizada. Isso, porém, soa estranho, evidentemente, e de fato legitimaria uma definição de “observável” como aquela proposta por Muller, pois, dessa forma, a observabilidade seria, sim, teoricamente dependente. Pior, a dependência teórica dela seria atestada pelo próprio Van Fraassen (e por Monton).

${ }^{12} \mathrm{E}$, ainda, sobre a distinção entre observável e inobservável, assinala ser ela "em parte funçẫo dos limites que a ciência revela sobre a observação humana.” (VAN FRAASSEN, 2007, p. 113). 
No artigo, todavia, apesar de Monton e Van Fraassen tratarem da necessidade de recorrer a nossas melhores teorias para responder à pergunta "O que é observável?”, os dois autores insistem que a observabilidade é uma questão empírica (um fato do mundo) e afirmam que, como Van Fraassen explicara, em "From vicious circle to infinite regress, and back again" (1992), já que a resposta a essa pergunta depende de fatos do mundo, o empirismo construtivo não é viciosamente circular (MONTON; VAN FRAASSEN, 2003, p. 414). Vamos tentar, então, uma análise desse passo diferente daquela de Muller, que levaria a pensar que Van Fraassen está se contradizendo de maneira importante (no âmbito da mesma página do artigo!) ou que, no mínimo, "escorregou" (de modo importante).

No texto de 1992, assim como em outros, Van Fraassen tinha deixado muito claro que a distinção entre observáveis e inobserváveis é empírica e não depende de nossas opiniōes a respeito da extensão do termo "observável". A consequência é que a adequação empírica de uma teoria é teoricamente independente. Entretanto, segundo afirma o filósofo holandês, quando alguém decide implementar a política epistêmica do empirismo construtivo, não se baseia na distinção que existe no mundo e, sim, na opiniáo que ele tem a esse respeito. Tal opinião será inevitavelmente condicionada pela linguagem que ele usa para formular todas as suas opinióes, inclusive os relatos observacionais. Essa linguagem, por sua vez, será "contaminada" por teorias que o sujeito (ou melhor, a comunidade linguística à qual pertence) endossa e que poderiam muito bem ser falsas (esse é um ponto sobre o qual Van Fraassen já tinha se detido, em $A$ imagem cientifica (VAN FRAASSEN, 2007, p. 37-38), explicando que, por causa da "impregnação teórica" da linguagem, a ideia positivista de realizar a distinção necessária para o empirismo em termos de vocabulário era obviamente inviável). Na prática, por isso, a correta aplicação da política epistêmica será influenciada por esses "vícios" da linguagem - assim como quando, antes de Lavoisier, um fenômeno real e observável, como a combustáo, era classificado como uma liberação de flogisto - e, por conseguinte, será perspéctica. Mas não existem alternativas; logo, isso não pode ser considerado um defeito (VAN FRAASSEN, 1992, p. 20).

Em vista de tudo isso, vale a pena salientar aquilo que Monton e Van Fraassen escreveram, no artigo de 2003. A asserção que eles fazem é a seguinte: "teorias diferentes fornecem respostas diferentes para a pergunta ' $\mathrm{O}$ que é observável?’. Na prática, portanto, devemos recorrer a nossas melhores teorias em uso para responder a essa questão." (MONTON; VAN FRAASSEN, 2003, p. 
414, tradução e ênfase nossas). A passagem continua com a afirmação de que, na teoria, uma vez que a comunidade epistêmica for especificada, a resposta à pergunta dependerá de fatos do mundo, remetendo ao artigo de Van Fraassen de 1992, para a demonstração de que isso implica que o empirismo construtivo não é viciosamente circular (MONTON; VAN FRAASSEN, 2003, p. 414). Nossas melhores teorias, em outras palavras, influenciam nossa opinião a respeito de onde cai a linha que separa aquilo que é observável daquilo que é inobservável (Monton e Van Fraassen evocam um âmbito dialógico, com efeito), mas não onde ela cai, de fato (obviamente).

Nossas opinióes acerca de fatos do mundo podem mudar, como de fato acontece, mas isso náo significa que o mundo mude com elas. É por isso que o conceito de observável é vago, porque nossa opinião a propósito da extensáo do termo não está ainda completamente formada, e não porque haja vagueza no mundo acerca de quais entidades são observáveis e quais são inobserváveis. A vagueza é epistêmica, não factual.

Existe, todavia, uma outra maneira de entender as passagens dos textos de Van Fraassen que Muller cita ou menciona, que é mais simples e que acreditamos ser aquilo que Van Fraassen tinha em mente, na verdade; porém, que significaria que Muller as entendeu de maneira equivocada (ou que forçou uma interpretação que servia para os seus propósitos). Tanto na seção "O círculo hermenêutico", no terceiro capítulo de $A$ imagem científica, quanto nas páginas do artigo "Constructive empiricism and modal nominalism", mencionadas por Muller, com efeito, Van Fraassen ressalta como delinear o observável no quadro do mundo pintado pela ciência. Nesses textos, aborda-se também como estabelecer o que é observável no plano empírico, mas em partes diferentes daquelas em questão. Ora, para sabermos o que a ciência considera como "observável", não há nada de mais natural e legítimo do que lançar mão das teorias científicas. Não há circularidade alguma em fazer assim, ainda mais tendo em vista que as teorias não postulam o que é observável, mas o revelam (VAN FRAASSEN, 2007, p. 111) citado anteriormente.

Para saber o que é observável tout court, ao invés, e não para saber o que é observável segundo certa teoria ou segundo a ciência, realiza-se uma pesquisa empírica, e o resultado será teoricamente independente (deixando de lado o fato de que os relatos da mesma pesquisa terão necessariamente algum grau de "contaminação teórica"). Nesse caso, tudo acontece no plano empírico. Utilizar-se de teorias para delinear no mundo o que é observável significaria, ao invés, confundir os planos de uma forma que levaria inevitavelmente a 
uma circularidade viciosa, caso os resultados disso fossem usados para julgar a adequação empírica das teorias.

Ora, o critério de Muller parece ter justamente a pretensão de estabelecer no plano empírico a extensão do predicado "observável”, e isso não pode ser correto, particularmente se a tentativa for feita a partir de uma teoria, segundo uma perspectiva top-down (podemos até "impor" nossos esquemas mentais ao mundo, como praticamente salientou Kant, mas isso não muda o mundo!). A determinação daquilo que é observável, diversamente, deve acontecer segundo uma direção bottom-up, do mundo para a teoria, se uma teoria deve servir para descrever corretamente os fenômenos. Atribuir a Van Fraassen uma suposta admissão de que a observabilidade é teoricamente dependente, enfim, pode servir para os objetivos de Muller, contudo, não parece correto.

Mais importante do que isso é que, sempre conforme Muller, a admitida dependência teórica daquilo que, segundo a sua própria definição, é observável, não levaria a um círculo vicioso (a catástrofe lógica que Van Fraassen receia), porque, sublinha ele, a teoria ondulatória da luz $(L)$ não foi aceita com base na distinção entre observável e inobservável que nela se encontra. Com efeito, ele continua, tal teoria diz muito mais do que quando um objeto é observável ou não e é esse "muito mais" que, historicamente, forneceu motivos para a aceitação de $L$ por parte da comunidade científica - e ainda fornece, acrescenta Muller (2005, p. 85).

Mas essa parece ser uma motivação bastante fraca, pois Muller propõe uma definição de observável que deveria servir para reforçar os alicerces do empirismo construtivo. Em vista disso, é realmente necessário que a comunidade científica tenha aceito a teoria ondulatória da luz $L$, sendo essa parte integrante da própria definição de Muller, sem a qual deixaria de ter sentido. Porém, segundo a reconstrução de Van Fraassen, a comunidade científica não aceita uma teoria pelo fato de esta dizer muito mais do que quando um objeto é observável ou não. A conditio sine qua non para que isso aconteça é que a teoria seja, além de informativa, empiricamente adequada (ou que, no mínimo, não se mostre "empiricamente inadequada", já que nunca podemos saber com certeza se uma teoria é de fato empiricamente adequada).

Com efeito, a única virtude exclusivamente epistêmica que uma teoria científica pode apresentar é a adequação empírica, de acordo com Van Fraassen, e, se ela não aparenta ter tal virtude, é descartada. ${ }^{13}$ Ora, conforme

${ }^{13}$ Já a informatividade parece ser um híbrido, sendo em parte epistêmica, em parte pragmática. 
a caracterização do próprio filósofo holandês, uma teoria é empiricamente adequada, se é verdadeiro o que ela diz sobre as coisas observáveis e eventos no mundo (VAN FRAASSEN, 2007, p. 34). Portanto, se endossada pela comunidade científica, a teoria ondulatória da luz $(L)$ é aceita, porque se julga que sua parte observacional descreve corretamente os fenômenos reais (e por outras consideraçóes de tipo pragmático, eventualmente), e estaríamos obviamente em presença de um círculo vicioso se utilizássemos a própria teoria $L$ para saber o que é observável e o que é inobservável no mundo. Eis a catástrofe lógica à qual alude Van Fraassen!

Em 2008, ademais, ele publicou um artigo em conjunto com Muller, no qual parece endossar a ideia de estender a política epistêmica do empirismo construtivo que apresentara, em 2004 e 2005 (MULLER; VAN FRAASSEN, 2008). ${ }^{14}$ Mas a nova proposta de extensão da "política epistêmica" não lança mão do critério de observabilidade sugerido por Muller. Como o texto deixa entender, com efeito, Van Fraassen considera inaceitável uma definição de observabilidade teoricamente dependente. ${ }^{15}$ Com razão, podemos rematar.

Vale, contudo, acrescentar que, para satisfazer plenamente Van Fraassen, a definição de Muller, se fosse aceitável, necessitaria provavelmente de uma pequena, mas importante modificação. Como pode ser depreendido de uma atenta leitura de $A$ imagem cientifica (VAN FRAASSEN, 2007, p. 42-45) e como foi reafirmado por Van Fraassen, em outros textos e ocasiôes (disse isso de forma muito clara em Belo Horizonte, em 2007, por exemplo) - e igualmente por outros autores, veja-se, particularmente, Bourgeois (1987, p. 307) -, é suficiente que, pelo menos, um membro da comunidade epistêmica tenha observado (ou seja capaz de observar) algo, para que tal fenômeno seja considerado observável para a comunidade como um todo.

Assim, a exigência de que todo e qualquer membro da comunidade epistêmica seja capaz de ver (observar) o objeto $X$, a qual se encontra na defi-

\footnotetext{
${ }^{14}$ Conforme escreve Paul Dicken, a resposta inicial de Van Fraassen à objeçáo levantada por Musgrave em 1985 foi, substancialmente, a de que o empirista construtivo náo precisa acreditar naquilo que as teorias aceitas dizem acerca dos inobserváveis (contrariamente à opinião de Musgrave), para traçar a distinçấo observável/inobservável. No entanto, o próprio Van Fraassen percebeu a necessidade de algo a mais e assim chegou-se à proposta de Muller e Van Fraassen de 2008 (DICKEN, 2010, p. 95-96).

${ }^{15}$ No artigo, é citado o passo no qual Muller salienta que o argumento de Musgrave está fundamentado na tácita assunçấo de que nossos julgamentos sobre a observabilidade de um objeto (existente ou não) devem basear-se em alguma teoria científica aceita (MULLER, 2004, p. 651, mencionado anteriormente), e a rejeição dessa pressuposição é abertamente declarada (MULLER; VAN FRAASSEN. 2008, p. 203).
} 
nição de Muller, é demasiado restritiva. Se, entre os membros da comunidade, houvesse um cientista cego, com efeito, nada seria visualmente observável! Isso se daria porque, segundo tal definição, os limites perceptivos da comunidade epistêmica coincidem com os limites perceptivos do seu membro mais limitado, já que todos os membros devem estar em condição de ver $X$. Segundo a ideia de Van Fraassen a esse respeito, diversamente, os limites perceptivos da comunidade epistêmica coincidem com os limites perceptivos do seu membro com as melhores capacidades.

A definição de Muller deveria, portanto, ser modificada e expressa assim: $\operatorname{Obs}(X, \varepsilon, L)$ sse $\exists p \in \varepsilon, \exists M \in L:(M, \operatorname{Frente}(p, X) \wedge \operatorname{Ve}(p, X))$. Essa fórmula, traduzida para a linguagem corrente, significa que certo objeto $X$ é observável (para a comunidade epistêmica $\varepsilon$ e considerando o subconjunto $L$ de modelos da teoria ondulatória da luz que contêm a comunidade epistêmica $\varepsilon$, uma fonte de luz e o objeto $X$ ), sse existe pelo menos um $p$, membro da comunidade epistêmica $\varepsilon$, e existe pelo menos um modelo $M$, entre aqueles do subconjunto $L$ de modelos da teoria, no interior do qual $p$ está na presença do objeto concreto $X$ e $p$ vê (observa) $X$.

Vale também frisar, neste ponto, que Muller considera, porém, que a comunidade epistêmica é constituída por pessoas com "olhos e mente saudáveis" (MULLER, 2005, p. 63) e que, por conseguinte, ele não aceitaria o exemplo do cientista cego. Contudo, para respaldar essa seletividade na composição da comunidade epistêmica, ele enfatiza fazer referência a Van Fraassen (1980, p. 18-19, 1985a, p. 253-258), e isso é realmente estranho, porque, em $A$ imagem científica, na página indicada por Muller, está claramente escrito: "No momento, consideramos a espécie humana como a comunidade epistêmica à qual pertencemos" (VAN FRAASSEN, 2007, p. 44), ao passo que, em "Empiricism in the philosophy of science", também na página à qual Muller garante fazer referência, lê-se: "Esses são limites gerais que eu considero aplicar-se independentemente de como nós (a comunidade epistêmica) somos e que, portanto, sempre existirão.” (VAN FRAASSEN, 1985a, p. 253, tradução nossa).

Em 1987, ademais, respondendo a uma objeção de Foss (1984), Warren Bourgeois explicou que não há nenhuma dificuldade para o empirista construtivo em admitir que uma comunidade contemple tanto pessoas com visão normal quanto pessoas cegas, pois essas últimas poderiam muito bem acreditar na existência de cores, e a justificação disso repousaria no simples fato de elas fazerem parte de uma comunidade em que há membros que con- 
seguem enxergar as cores das coisas. "É óbvio que diferentes membros de uma determinada comunidade terão diferentes capacidades de observar" - escreve Bourgeois -, "mas observabilidade para um é observabilidade para todos." (BOURGEOIS, 1987, p. 307, tradução nossa).

Similarmente, William Seager (1988, p. 181) destaca:

Os membros de uma comunidade epistêmica devem cada um respeitar as capacidades epistêmicas do outro. Em segundo lugar, as crenças de um outro membro da mesma comunidade garantem a crença [...] de cada membro. Tais crenças representam uma parte da imagem do mundo que nós almejamos desenhar, mas que, graças ao esforço de outros, não precisamos desenhar sozinhos. (Tradução nossa).

Basta que pelo menos um membro tenha observado (ou seja capaz de observar) tal fenômeno, para que ele seja considerado observável para a comunidade como um todo. Isso foi reafirmado, de forma a não deixar dúvidas, por Van Fraassen, em 1992:

O termo "observável” é muito parecido com outros termos comuns como "portátil" e "frágil". Eles são, por assim dizer, termos antropocêntricos, pois se referem a nossas limitaçóes. Eles não são pessoa-cêntricos, porém; computadores laptop são portáteis e copos de vinho frágeis, mesmo que algumas pessoas sejam demasiado fracas para carregá-los ou até quebrá-los. (VAN FRAASSEN, 1992, p. 18-19, tradução nossa).

Em outro artigo de Van Fraassen, o já mencionado "The day of the dolphins. Puzzling over epistemic partnership", enfim, a ideia de que a comunidade epistêmica seja constituída pela raça humana como um todo, e não por um grupo seleto de pessoas, está ulteriormente reafirmada.

Ainda assim, quando Muller forneceu sua definição rigorosa de "observável", ele o fez passando de uma formulação do "guia grosseiro" legítima, porque equivalente àquela fornecida por Van Fraassen, a uma expressa em linguagem lógica (como foi visto na seção anterior), declarando: "Nós definimos agora a observabilidade de forma precisa, traduzindo esse Novo Guia Grosseiro na linguagem da teoria ondulatória da luz, que inclui o conhecimento cientifico relevante nesse caso." (MULLER, 2005, p. 82-83, tradução e grifo nosso). Mas sua passagem de uma formulação "grosseira" (rough) para uma formalizada (que chama, justamente, de definição) não pode ser considerada uma tradução, porque nela se perde a característica mais importante, a qual, 
para Van Fraassen, a observabilidade tem, a saber, a independência das teorias. A definição de Muller, ao contrário, como ele mesmo admite e foi visto, é teoricamente dependente.

No entanto, o fato de as duas formulaçóes de Muller não serem equivalentes não se deve somente à perda da independência teórica, a qual já discutimos. Considerar que as circunstâncias "que existem no mundo" (que Van Fraassen chama de condiçóes) correspondam aos modelos da teoria ondulatória da luz (segundo uma ascensão bottom-up, do mundo para a teoria) é problemático, porque é bem possível que não subsista um isomorfismo entre as duas classes e que o conjunto das circunstâncias "no mundo" seja mais amplo do que aquele dos modelos permitidos pela teoria ondulatória da luz. ${ }^{16}$

Enfim, a definição de Muller não pode ser (e não foi) acatada. Entretanto, a sua ideia de que o empirismo construtivo necessitaria de uma nova "política epistêmica" parece ter sido endossada até por Van Fraassen, no artigo que os dois escreveram, em 2008. Todavia, apesar de aparentemente permitir resolver (finalmente) o "problema de Musgrave", uma nova política epistêmica parece supérflua. Nunca existiu, de fato, para o empirismo construtivo, um "problema" como aquele levantado por Musgrave e elaborado por Muller.

\section{Conclusấo: o “problema de Musgrave” É na Verdade um PSEUdoproblema}

Independentemente de questôes acerca da legitimidade da pressuposição de Musgrave, segundo a qual nossos julgamentos sobre a observabilidade de um objeto devem fundamentar-se em alguma teoria científica aceita, a conclusão do argumento dele (um empirista construtivo não pode acreditar que os elétrons são inobserváveis, segundo a versão de Muller) parece falsa. Não somente um empirista construtivo pode legitimamente acreditar em todas as proposiçôes de uma teoria aceita que digam respeito à observabilidade de entidades que ela postula (por elas serem "verdades sintéticas", as quais podem ser verificadas pela observação; a aceitação da teoria, aliás, decorre dessa verificação), como também pode legitimamente acreditar em todas as proposiçóes da mesma teoria que digam respeito à inobservabilidade de entidades por ela postuladas.

\footnotetext{
${ }^{16}$ Agradeço ao Prof. Otávio Bueno, da University of Miami (EUA), por ter sugerido a presença dessa segunda dificuldade na "traduçăo" de Muller.
} 
No caso da proposição "elétrons são inobserváveis", por exemplo, já que a definição/postulação de elétron que as teorias normalmente fornecem elenca "somente" as características salientes do mesmo (massa, carga, raio, onde ele orbita etc.), o fato de esse corpúsculo ser inobservável é uma consequência dedutível dessa postulação (juntamente com algumas premissas adicionais) e a proposição em questão se torna necessariamente verdadeira, independentemente da questão da existência da partícula. Por essa razão, o empirista construtivo pode acreditar nela (porque ele pode acreditar inclusive em "verdades lógicas", obviamente, conforme já foi destacado).

Obviamente, se a teoria diz que o raio do elétron é $2,8179 \times 10^{-15} \mathrm{~m}$ (é esse o valor do chamado "raio clássico do elétron"), não há necessidade de se acreditar nisso (e nem possibilidade, segundo os ditames do empirismo construtivo, visto que essa informação não pode ser verificada pela observação e nem se trata de uma consequência dedutível da postulação da partícula). O empirista construtivo aceita isso, porém, se aceitou a teoria como um todo. Ora, a inobservabilidade do elétron decorre logicamente da postulação do mesmo - e de alguma informação complementar acerca das capacidades perceptivas humanas (dizer "elétrons são inobserváveis" é a mesma coisa que dizer que essas partículas têm um tamanho inferior ao limite mínimo que o olho consegue discernir e, portanto, não podemos vê-los) - e pode-se, portanto, legitimamente acreditar em proposiçôes onde isso é afirmado. ${ }^{17} \mathrm{O}$ "problema de Musgrave", enfim, nunca existiu de fato.

É oportuno, todavia, encerrar admitindo que é bem possível que Van Fraassen tivesse em mente tudo isso que acabamos de abordar, quando escreveu o artigo em parceria com Muller. Não está totalmente claro, com efeito, que ele realmente endosse a ideia da necessidade de uma "política epistêmica" para o empirismo construtivo, a despeito de o que Muller fez, em 2004 e 2005, ter sido simplesmente formalizar, no molde de uma política epistêmica, aquilo que está afirmado em $A$ imagem cientifica. Ou melhor, aquilo que ele acha estar afirmado em $A$ imagem cientifica (e nisso está na companhia de Musgrave).

O que está escrito na página conclusiva de "How to talk about unobservables" é que foi Muller a propor uma política epistêmica para responder à

\footnotetext{
${ }^{17} \mathrm{O}$ argumento poderia ser expresso da seguinte forma: o limite de resolução angular do olho humano é, aproximadamente, de $0,07^{\circ}$; independentemente de quanto nos aproximamos de um elétron (?), seu tamanho é tal que a resolução angular que podemos obter do mesmo é $<<0,07^{\circ}$ (é zero, de fato!); logo, nenhum ser humano pode ver um elétron.
} 
pergunta "Se você aceita uma teoria T, então acredita no quê?" e a dizer que ela faz parte do empirismo construtivo. Não obstante, ela não permite chegar a crenças como "elétrons são inobserváveis" e, para que isso se torne possível, precisa ser complementada. Daí, para emendar aquela de Muller, a nova proposta, que é dita ser "perfeitamente compatível com o espírito do empirismo construtivo.” (MULLER; VAN FRAASSEN, 2008, p. 204, tradução nossa).

Ora, a "regra zero" que deveria constituir o complemento da "política epistêmica" inicial de Muller - "Se você aceita $T$ e $Y$ é (in)observável segundo T, então acredite nisso" (MULLER; VAN FRAASSEN, 2008, p. 204, tradução nossa) - é sem dúvida perfeitamente compatível com o espírito do empirismo construtivo e já foi explicado o porquê. No artigo, entretanto, essa afirmação não foi qualificada. É possível que ela tenha sido considerada óbvia, todavia, dedicar algumas palavras a esse respeito teria ajudado a evitar que a nova política epistêmica proposta deixasse a impressão de ser uma solução ad hoc para o "problema de Musgrave".

Não somente essa sensação pode ser gerada pela forma da "regra zero", com efeito, uma vez que existem outras proposiçóes, entre aquelas que Muller chamaria de "não-empíricas", nas quais um empirista construtivo pode legitimamente acreditar, como também é reforçada pela frase de encerramento do artigo: "Isso é suficiente para resolver o problema de incoerência estendido." (MULLER; VAN FRAASSEN, 2008, p. 204, tradução nossa).

Nossa opinião é que Van Fraassen poderia ter salientado o fato de que a política epistêmica que Muller entendeu fazer parte do empirismo construtivo, nos artigos de 2004 e 2005, na verdade náo espelhava as ideias contidas em $A$ imagem científica. No livro, Van Fraassen definiu a sua posição antirrealista, afirmando que a ciência visa dar-nos teorias que sejam empiricamente adequadas; e a aceitação de uma teoria envolve, como crença, apenas aquela de que ela é empiricamente adequada (VAN FRAASSEN, 2007, p. 33, grifo do autor); ou, dito de outra maneira, a crença de que aquilo que a teoria diz sobre as coisas e dos eventos observáveis (e reais) desse mundo corresponde à verdade. Mas isso também significa que a quantidade de crença envolvida no aceitar uma teoria cientifica é somente a de que essa "salva os fenômenos", ou seja, descreve corretamente aquilo que é observável [cf. também Van Fraassen (2007, p. 20, 160, 344)]. Isso quer dizer que um empirista construtivo deve acreditar somente naquilo que a teoria aceita diz acerca do observável? Não. A crença de que a teoria é empiricamente adequada é uma crença adicional. Em nenhum ponto de $A$ imagem cientifica Van Fraassen prescreve que um empi- 
rista construtivo somente acredite naquilo que a teoria diz a respeito da parte observável do mundo. Ao invés, aquilo que ele diz (novamente) é o seguinte: "aceitar uma teoria náo envolve mais crença de que o que a teoria diz sobre os fenômenos observáveis é correto" (VAN FRAASSEN, 2007, p. 111); (mas vejam-se também as páginas $20,33,43-44,48,160,266,313,344,350-351$ ). Acreditar que é verdadeiro aquilo que a teoria diz acerca dos observáveis reais corresponde à quantidade de crença envolvida no aceitar uma teoria. Isso é algo que Van Fraassen afirma repetidamente, em seu livro. Nunca realçou, porém, que a quantidade de crença envolvida no endossar o empirismo construtivo corresponde somente à quantidade de crença envolvida no aceitar uma teoria. Um empirista construtivo pode assim acreditar (legitimamente) que dezessete é um número primo e até que os elétrons são inobserváveis, pace Musgrave (e Muller)!

Aquilo que, na realidade, precisava ser emendado era, portanto, a ideia de Muller sobre a suposta "política epistêmica" do empirismo construtivo. O mesmo se diga quanto à opiniâo de Dicken e Lipton, segundo os quais, se a crença na adequaçáo empírica de uma teoria implica a crença da verdade de sentenças como " $X$ é inobservável", então Musgrave poderia responder que a crença na adequação empírica já transcende as restrições que o empirista construtivo está tentando respeitar (DICKEN; LIPTON, 2006, p. 232). Essa opiniáo parece decorrer da mesma ideia equivocada acerca de qual seria a política epistêmica do empirismo construtivo, como se um empirista construtivo somente pudesse acreditar nas proposiçóes de uma teoria aceita que Muller batizou de "empíricas".

Van Fraassen, enfim, poderia ter rejeitado as ideias de Muller tout court e não somente sua definição de "observável". A política epistêmica emendada, sugerida na última página do artigo de 2008, é supérflua, porque nada acrescenta àquilo que já podia ser implicitamente (ou até explicitamente) depreendido de uma atenta leitura de $A$ imagem cientifica. Pior do que isso, ela se apresenta como solução ad hoc para um problema específico ${ }^{18}$ e, sobretudo,

\footnotetext{
${ }^{18}$ Essa parece ser também a opinião de Dicken: "A resposta de Muller e Van Fraassen à objeção de Musgrave [...] depende da atribuição de um estatuto privilegiado àquilo que as teorias científicas aceitas por um empirista construtivo dizem acerca da observabilidade; essa atribuição, embora não necessariamente ad hoc, certamente carece de qualquer motivaçáo independente." (DICKEN, 2010, p. 97, tradução nossa). Nessa passagem, Dicken não acusa abertamente a "política epistêmica emendada" de Muller e Van Fraassen de ser ad hoc, porém, pouco à frente, na mesma página, acaba fazendo isso, ao frisar que atribuir a essa classe reduzida um estatuto modal privilegiado "não tem absolutamente nenhuma outra motivação a não ser evitar a objeção de Musgrave.” (DICKEN, 2010, p. 97, tradução nossa).
} 
não "captura" tudo aquilo no qual um empirista construtivo pode legitimamente acreditar.

As objeçóes de Musgrave e Muller "colocavam o dedo na ferida", ou assim eles acreditavam, porque foram levantadas a propósito de afirmaçóes sobre o estatuto observacional de entidades postuladas por uma teoria; e esse estatuto tem um peso especial no âmbito do empirismo construtivo, tendo em vista que, conforme foi visto ao longo deste trabalho, a aceitação de uma teoria científica envolveria a crença de que aquilo que esta assevera a propósito das partes observáveis do mundo é verdadeiro, enquanto o resto "não interessa" (VAN FRAASSEN, 2005, p. 111, 2007). Todavia, outras proposiçóes de uma teoria aceita, acerca de entidades inobserváveis por ela postuladas (e não somente), podem ser consideradas verdadeiras, mesmo que não tenham o mesmo "peso epistêmico" daquelas sobre o estatuto observacional. Basta que o que elas afirmam decorra logicamente de alguma "propriedade definitória” da entidade em questão (às vezes, acompanhada de outras premissas), como no exemplo anterior do elétron, para que um empirista construtivo acredite nelas (como faria qualquer um).

"Submetida a uma temperatura superior a $100^{\circ} \mathrm{C}$, uma célula humana morre", "Nenhum fóton pode deslocar-se a uma velocidade superior a $9 \times 10^{8}$ $\mathrm{m} / \mathrm{s}$ ", "Uma molécula de água pesa menos que uma mioglobina" são exemplos de proposiçóes nas quais qualquer pessoa pode acreditar, inclusive um empirista construtivo - e sem que isso implique qualquer tipo de comprometimento ontológico. Trata-se de consequências lógicas das teorias que definem as entidades em questão, decorrentes da própria postulação dessas e de eventuais outras premissas adicionais. Aliás, para que se possa acreditar na verdade de alguma sentença, nem há necessidade de essa fazer parte de alguma teoria aceita. Com efeito, é legítimo igualmente acreditar em afirmações como "Sherlock Holmes nunca deu à luz uma menina" ou "O calórico não tem cheiro de baunilha”. Esses são enunciados que decorrem de características definitórias das entidades em questão (mais a premissa de que homens não podem parir, no exemplo de Sherlock Holmes) e, por essa mesma razão, a crença na verdade deles é justificada.

Tudo isso já fazia parte da conduta de um empirista construtivo desde a publicação de $A$ imagem cientifica e poderia ter sido reafirmado. No entanto, Van Fraassen resolveu escrever "How to talk about unobservables", em parceria com Muller, dez anos atrás, para propor uma emenda à política epistêmica desse. Pode ser que o objetivo fosse simplesmente mostrar quais "postulados 
epistêmicos" do empirismo construtivo permitem solucionar o "problema de Musgrave", mas nossa opinião é que teria sido mais simples mostrar que, dado o que está escrito em $A$ imagem cientifica, esse suposto problema na verdade nem poderia surgir - e o mesmo diga-se para eventuais outros argumentos, análogos àquele de Musgrave, que possam concernir a proposiçôes que correspondem a deduçóes lógicas de alguma premissa dada.

GAVA, A. Constructive empiricism and Musgrave's argument: problem or pseudoproblem? Trans/form/ação, Marília, v. 41, n. 4, p. 177-204, Out./Dez., 2018.

ABSTRACT: In 1985, Alan Musgrave raised a serious objection against the possibility that a constructive empiricist could coherently draw the distinction between observables and unobservables. In his brief response in the same year, Bas van Fraassen claimed that Musgrave's argument only works within the so-called 'syntactic view' of theories, while it loses its force in the context of the 'semantic view'. But this response was not adequate, or so claimed F. A. Muller, who published two articles (2004 and 2005) in order to extend the epistemology of constructive empiricism. In order to do so, Muller provided a rigorous characterization of observability that requires the use of modal logic. The outcome was a new (extended) epistemology for constructive empiricism, which van Fraassen apparently endorsed (cf. Muller \& van Fraassen 2008). As will be shown in this article, however, Muller's extended epistemology is superfluous. Moreover, and more importantly, Musgrave's argument seems to be a pseudo-problem.

KeYwords: Constructive empiricism. Epistemology. Observability. Musgrave’s problem. Bas van Fraassen.

\section{REFERÊNCIAS}

BOURGEOIS, W. Discussion: on rejecting Foss's image of Van Fraassen. Philosophy of Science, v. 54, n. 2, p. 303-308, 1987.

DICKEN, P. Constructive empiricism: epistemology and the philosophy of science.

Basingstoke, England: Palgrave Macmillan, 2010.

.; LIPTON, P. What can Bas believe? Musgrave and Van Fraassen on observability. Analysis, v. 66, n. 3, p. 226-233, jul. 2006.

FOSS, J. On accepting Van Fraassen's image of science. Philosophy of Science, v. 51, n. 1, p. 79-92, mar. 1984. 
GIERE, R. N. Essay review: scientific representation and empiricist structuralism. Philosophy of Science, v. 76, n. 1, p. 101-111, 2009.

MONTON, B.; Van FRAASSEN, B. C. Constructive empiricism and modal nominalism. British Journal for the Philosophy of Science, v. 54, n. 3, p. 405-422, 2003.

MULLER, F. A. Can a constructive empiricist adopt the concept of observability? Philosophy of Science, v. 71, n. 1, p. 637-654, 2004.

. The deep black sea: observability and modality afloat. British Journal for the Philosophy of Science, v. 56, n. 1, p. 61-99, 2005.

MULLER, F. A.; Van FRAASSEN, B. C. How to talk about unobservables. Analysis, v. 68, n. 3, p. 197-205, 2008.

MUSGRAVE, A. Realism versus constructive empiricism. In: CHURCHLAND, P. M.; HOOKER, C. A. (Ed.), Images of science: essays on realism and empiricism, with a reply from Bas C. van Fraassen. Chicago: The University of Chicago Press, 1985. p. 197-221.

PSILLOS, S. Scientific realism: how science tracks truth. London; New York: Routledge, 1999.

SEAGER, W. Scientific anti-realism and the epistemic community. In: PSA: THE BIENNIAL MEETING OF THE PHILOSOPHY OF SCIENCE ASSOCIATION. 1988. Chicago. Proceedings... Chicago: University Chicago of Press, 1988. V. 1. p. 181187.

SICHA, J. F. (Rev.) Reviewed work. Images of science: essays on realism and empiricism, with a reply from Bas C. van Fraassen by P. M. Churchland; C. A. Hooker. Nô̂u, n. 26, p. 519-525, 1992.

Van FRAASSEN, B. C. The scientific image. Oxford: Clarendon Press, 1980.

. Empiricism in the philosophy of science. In: CHURCHLAND, P. M.;

HOOKER, C. A. (Ed.). Images of science: essays on realism and empiricism, with a reply from Bas C. van Fraassen. Chicago: The University of Chicago Press, 1985a. p. 245-308.

. Prefazione all'edizione italiana. Tradução de Roberto Festa. In:

L'immagine scientifica. Bologna: Editrice CLUEB, 1985 b.

. From vicious circle to infinite regress, and back again. In: PSA: BIENNIAL MEETING OF THE PHILOSOPHY OF SCIENCE ASSOCIATION. 1992 Chicago. Proceedings... Chicago; University of Chicago o Press, 1992. V. 2. p. 6-29.

. Preface to the Greek edition. 2004. Disponível em: <http://www.princeton. edu/ fraassen/Sci-Img/ Sci_ImagePrefaceGreek.pdf>. Acesso em: 11 jun. 2007.

. The day of the dolphins. Puzzling over epistemic partnership. In: IRVINE, A.; PEACOCK, K. (Ed.), Mistakes of reason: essays in Honour of John Woods. Toronto: University of Toronto Press, 2005. p. 111-133. 
GAVA, A.

A imagem cientifica. Tradução de Luiz Henrique de Araújo Dutra. São Paulo:

Editora UNESP; Discurso Editorial, 2007.

Scientific representation: paradoxes of perspective. Oxford: Clarendon Press, 2008.

Recebido: 01/05/2017

Aceito: 25/09/2017 